\title{
Modulation of Reflex Activity of Motor Units in Response to Stretch of a Human Finger Muscle
}

\author{
Kazuyuki Kanosue, Kenzo Akazawa, ${ }^{*}$ and Katsuhiko Fujiı* \\ Department of Physiology, Osaka University Medical School and \\ *Department of Electrical Engineering, Faculty of Engineering, \\ Osaka University, Osaka, 530 Japan
}

\begin{abstract}
Changes in stretch reflex responses were examined in two types of motor task, force control and position control, by applying a small quick stretch to the middle finger extensor digitorum communis (EDC) muscle at an unpredicted time and observing activities of single motor units. Subjects were asked to maintain a constant extending isometric force at the metacarpophalangeal (MP) joint for force control, and to maintain a constant middle finger position against an applied force for position control. No significant differences in the tonic activities of EDC motor units were seen between the two types of motor task when the same force was exerted about the MP joint. Tonic activities of the EDC muscle and its antagonists were thus similar for both types of motor task. Ten of the eighteen motor units investigated showed obvious reflex responses (increase in firing rate) with latencies of $30-60 \mathrm{msec}$ after the stretch. This reflex response was greater for position control than for force control, given the same operating conditions of tonic force, finger position, and activities of motor units. Enhancement of the stretch reflex for position control was also observed in surface electromyograms of the same muscle.
\end{abstract}

Key Words: stretch reflex, motor unit activity, surface EMG, finger muscle, normal human subjects.

From the first study of HAMMOND (1956), it has been extensively investigated whether or not stretch reflex responses are modulated according to types of motor task (Hagbarth, 1967; Evarts and TANJi, 1974; Crago et al., 1976; Evarts and Granit, 1976; Iles, 1977; Colebatch et al., 1979; Gottlieb and AgARWAL, 1979; RothWell et al., 1980). In these studies, subjects were instructed to react in one of two contrasting ways to the occurrence of a mechanical disturbance, e.g., either to resist or to ignore the disturbance. Changes in the long latency stretch reflex response by virtue of the instruction were observed, but the gain of the short latency

Received for publication April 22, 1983

彼末一之, 赤沢堅造, 藤井克彦 
reflex (myotatic reflex) could hardly be affected by such a difference in instructions. The operating force of the muscle, however, could change the gain of the myotatic reflex to a great extent (Gottlieb and Agarwal, 1979).

In the present work, by observing the reflex responses in single motor units and in electromyograms (EMGs) to quick stretches of a human finger muscle, we further examined the question of whether the gain of the short latency reflex loop could be modulated by changing the nature of the motor task. We investigated short latency reflex responses for two kinds of motor task-force control and position control. In force control, each subject was asked to maintain a constant net force under isometric conditions. In position control, the subject was asked to maintain a constant finger position and thus a corresponding muscle length against an external load. A disturbance, in the form of a quick stretch, was introduced at an unpredicted time during the execution of these motor tasks, and the subject was always instructed not to react to the disturbance.

These two motor tasks were chosen for the following reasons. In general, large stiffness in a controlled system is desirable for precisely regulating position, whereas less stiffness is required for regulating force. If the stretch reflex operates as a length servo, the gain or stiffness of the reflex loop might be enhanced during execution of position control and depressed for the force control task. If the higher motor centers can modulate reflex gain, the stretch reflex response for position control would thus be larger than for force control. Because stretch reflex responses with latencies greater than $60 \mathrm{msec}$ might involve a voluntary reaction component (Houk, 1979; RoTHWELl et al., 1980), we examined only responses with latencies of less than $60 \mathrm{msec}$.

Results of preliminary work have already been reported (KANOSUE et al., 1980).

\section{METHODS}

The experiments were carried out on the left hand middle finger extensor digitorum communis (EDC) muscle of four normal male right-handed adults ranging from 22 to 37 years of age. The experimental apparatus is shown in Fig. 1. The forearm was horizontally placed on a plaster cast fitted for each individual subject. The hand was fixed on an iron plate with leather straps, the palm held vertically with the thumb upward. Only the middle finger was allowed to move freely in the horizontal plane around the metacarpophalangeal (MP) joint. A light, thin aluminium plate $(1 \times 8 \times 0.1 \mathrm{~cm})$ was fastened to the dorsal surface of the middle finger to fixate the interphalangeal joints in extension. The angle between the palm and relaxed middle finger was approximately 135 degrees. The tip of the middle finger touched an iron lever that rotated in the horizontal plane. Friction torque around the axis of the lever was very low (less than $3 \times$ $10^{-5} \mathrm{~N} \cdot \mathrm{m}$ ). The lever was adjusted so that its angle of rotation equalled that 

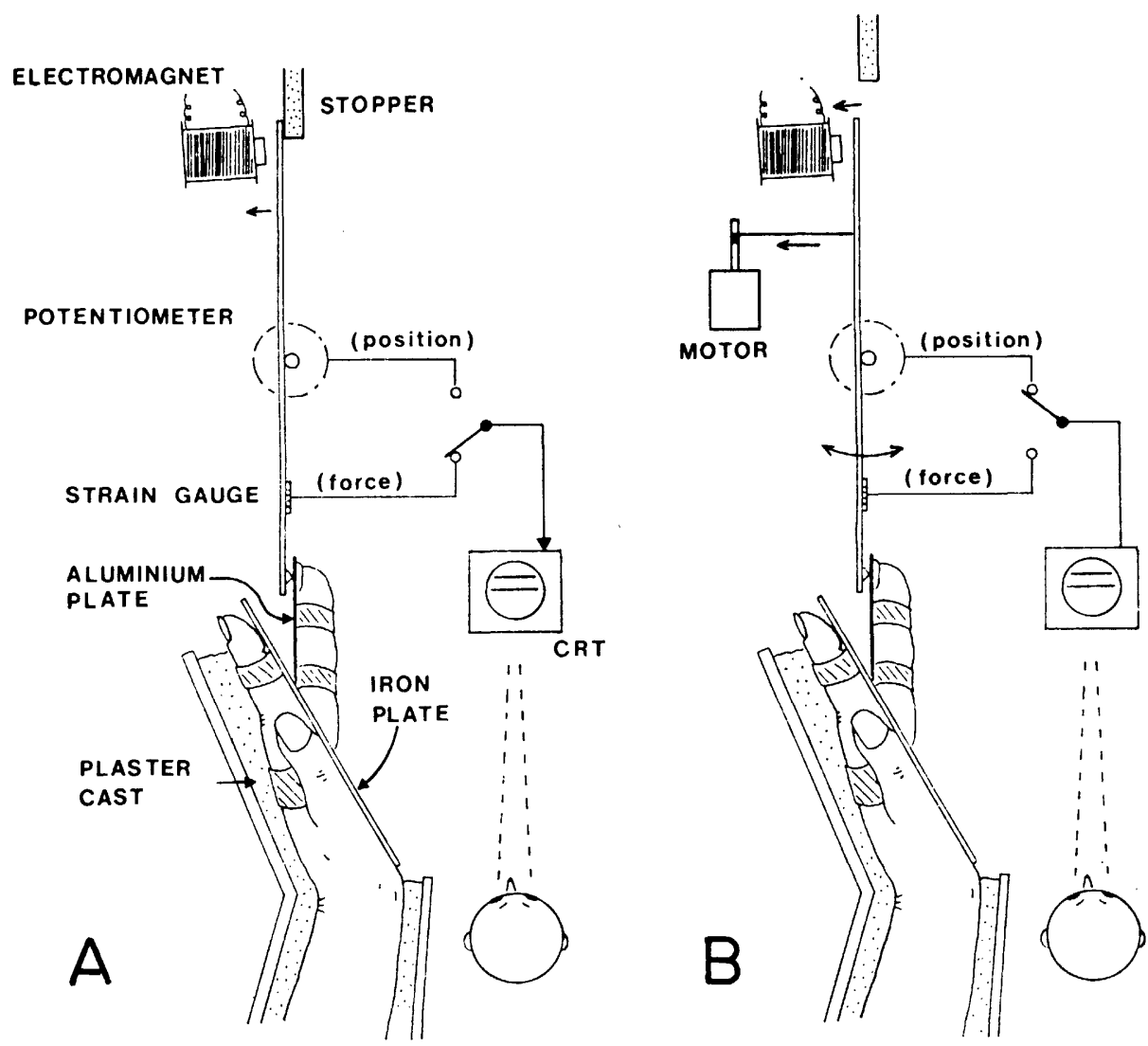

Fig. 1. Schematic diagram of the experimental apparatus (top view). Middle finger position (angle of the metacarpophalangeal joint) is measured with a precision potentiometer connected to the lever axis, and the net force exerted by the middle finger is indicated with strain gauges. A. Force control: the subject is asked to maintain a constant isometric force of middle finger extension. A stopper prevents lever movement. Output of the strain gauges is displayed on an oscilloscope for visual feedback of the net force. $B$. Position control: the subject is asked to keep his middle finger at a constant position against force generated by an AC motor. The stopper is removed in this case. Output of the potentiometer is displayed on the oscilloscope as a visual feedback signal of finger position. An electromagnet produces a small stepwise displacement of the lever, which forcibly flexes the finger.

of the MP joint over a small range of angular displacement. The lever was set parallel to the resting middle finger, whose position was arbitrarily designated 0 degrees. The distance between the MP joint and the contact point was $8 \mathrm{~cm}$, identical to that between the contact point and the axis of rotation for the lever.

Force and position recordings. Force exerted by the middle finger was measured by strain gauges mounted on the lever. The mechanical response was 
expressed as a force in newtons $(\mathrm{N})$ measured at the tip of the middle finger, rather than as a torque in newton-meters $(\mathrm{N} \cdot \mathrm{m})$. The constant value of the lever arm length of $8 \mathrm{~cm}$ can be used to convert from force to torque. Position of the middle finger was measured by a precision potentiometer which monitored angular position of the lever. The middle finger position was expressed as an angle in degrees, measured at the axis of the lever; the angle of the lever closely approximated the rotation angle of the MP joint because the excursion of angular displacement did not exceed 2 degrees.

Single unit and surface EMG recordings. Single motor unit activities were recorded from the left middle finger EDC muscle using bipolar fine-wire electrodes made from polyurethane-insulated copper wire of $50 \mu \mathrm{m}$ diameter (BASMAJIAN, 1974). Amplified motor unit discharges were displayed on a monitor scope and were also monitored with an audio-speaker. The wire electrodes were located exactly in the middle finger EDC muscle, so that motor unit activities of the muscle could be clearly observed. This was confirmed as follows: i) motor unit activities observed when the subject voluntarily extended the middle finger isometrically were much stronger than those when he extended any of the other three fingers, and ii) close correlation between the isometric force and the firing rate of a single motor unit was obtained (see Fig. $3 \mathrm{C}$ ).

In some experiments, surface EMG activities of the same muscle were recorded with a pair of electrodes (silver chloride disk $1 \mathrm{~cm}$ in diameter) attached on the skin surface over the muscle. The EMG signals were amplified, full wave rectified, and filtered with a low-pass filter (time constant $30 \mathrm{msec}$ ).

Force control and position control. The two kinds of motor task, force control and position control, were performed as follows. In force control (Fig. 1 A), the subject was asked to maintain a constant isometric force. The iron lever was clamped with a stopper at 0 degrees to prohibit further finger extension. To provide the subject with visual feedback of the force, the strain gauge output was displayed on one channel of an oscilloscope, and a reference force to be matched was displayed simultaneously on the second channel. In position control (Fig. $1 \mathrm{~B})$, the subject was asked to maintain the finger at 0 degrees against a force generated by an $\mathrm{AC}$ motor. The subject could move his finger freely because the stopper was removed. Output of the potentiometer and the 0 degree position were displayed simultaneously on the oscilloscope as visual feedback signals to the subject. Two kinds of external force were applied for position control. For constant load position control, the external force was constant regardless of the finger position. For unstable load position control, the external force generated by the AC motor increased in proportion to the magnitude of finger flexion. The load at 0 degrees was the same as that for the corresponding constant load position control task, but the increase in external force to flex the finger as the finger progressed further into flexion created an unstable situation, making it difficult for the subject to maintain the finger at 0 degrees. This variability of ex- 


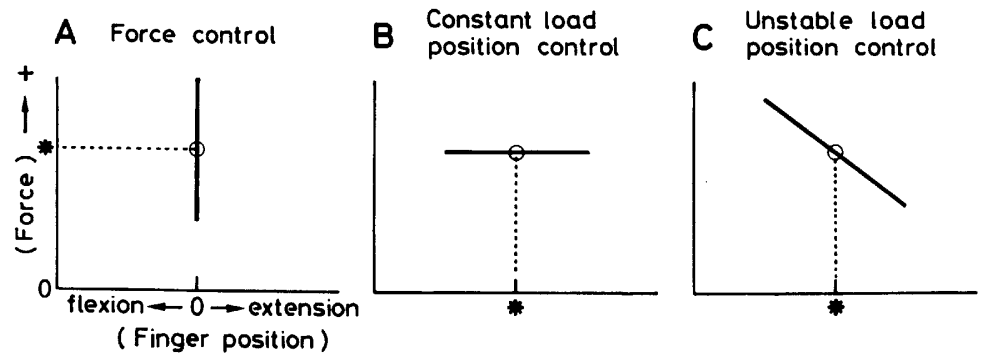

Fig. 2. Position-force relation of the external load in three types of motor task are shown with thick lines. The controlled variable is force in the force control task and position in the position control tasks. Reference values (desired value of force or position) are shown with asterisks, and desired operating points with open circles. See text for details.

ternal force was produced by building positive feedback with a gain of $0.5 \mathrm{~N} /$ degree into the AC motor system. The unstable load position control task was incorporated into the experiment, because by making the controlled system unstable, the subject would have to enhance the stretch reflex response to stabilize the finger.

Differences in the dynamic properties of the load among force control, constant load position control, and unstable load position control are shown in Fig. 2. For force control, the finger was clamped at 0 degrees, so the position-force relation of the controlled system is represented by the thick line in Fig. $2 \mathrm{~A}$. The subject tried to keep the force at a reference level (shown by an asterisk), so the controlled variable was force. For constant load position control, the external load was constant regardless of finger position (Fig. 2 B). The subject had to try to keep the finger at 0 degrees (shown by an asterisk), so the controlled variable for this task was finger position. For unstable load position control, the controlled variable again was finger position, but the external load changed with finger position as indicated in Fig. $2 \mathrm{C}$.

Stretch reflex. To elicit a stretch reflex response during either the force control or the position control task, we applied a small stepwise rotation to the lever ( 2 degrees; $2.8 \mathrm{~mm}$ displacement of the finger tip) in the direction of stretching the EDC muscle (flexion of the finger) as the subject was maintaining a constant force or a constant finger position. The lever rotation, which was produced by an electromagnet, required less than $12 \mathrm{msec}$. The disturbance was delivered in such a way that the subject could not accurately predict its time, so effects of voluntary reaction on the short latency stretch reflex were negligibly small (Rothwell et al., 1980). The subject was instructed to perform the motor task of force control or position control only over the period prior to the delivery of the disturbance, not to react to the disturbance itself, and not to attempt to maintain force or finger position after the delivery of the disturbance.

Five trials of force control were first conducted, followed by five trials of constant load position control. In some cases, five trials of unstable load posi- 
tion control were added. The entire sequence of trials was then repeated. Each motor task was thus performed ten times. There was a rest period of about $1 \mathrm{~min}$ between trials. The initial force (reference force in force control or externally applied force in constant load position control) was adjusted so that discharges of a single motor unit could be clearly discerned (Fig. 4). In most cases, the force was less than $2 \mathrm{~N}$, whereas the maximum isometric force of voluntary contraction was approximately $10 \mathrm{~N}$. Once determined, the initial force was set constant throughout a given series of experiments.

Data analysis. All the data were stored on an FM magnetic tape recorder (TEAC R-260) and later fed into a minicomputer (MELCOM 70/25) with a sampling rate of $32 \mathrm{kHz}$ for motor unit action potentials and of $1 \mathrm{kHz}$ for position, force, and suface EMG. Action potentials were displayed on a graphic computer terminal (Tektronix 4051) and individual motor unit was identified visually by the wave form of the displayed action potentials.

In the stretch reflex experiments, data analysis was limited to the period between $200 \mathrm{msec}$ prior to the onset of the disturbance and $300 \mathrm{msec}$ after the onset. The ten responses of position, force, and surface EMG were averaged for each type of motor task.

Single motor unit activities were analysed in three successive stages. Note that the time $t=0$ refers to onset of the disturbance. First, instantaneous firing rates were calculated from interspike intervals of successive discharges in each trial; that is, denoting the time of the $k$-th discharge by $t_{k}$ the instantaneous firing rate $f_{k}$ at $t_{k}$ is expressed by

$$
f_{k}=1 /\left|t_{k}-t_{k-1}\right| \text {. }
$$

Secondly, the instantaneous firing rates of 10 trials were superposed with respect to the time of onset of the disturbance and plotted as in the third traces of Figs. 5 and 6 . As seen from the figures, the plotted points are too dispersed to allow for an immediate quantitative interpretation of the response. The third stage was thus required to smooth the data, and this was done by calculating a moving average for groups of five points. If the firing rate and the time of the $i$-th point in the third trace are represented by $f_{i}$ and $t_{i}$, respectively $(i=1,2, \cdots, N), t_{i}>$ $t_{i-1}$, the moving average of firing rate $\bar{f}\left(t_{i}\right)$ at the time $t_{i}$ was calculated as

$$
\tilde{f}\left(t_{i}\right)=\frac{1}{5} \sum_{j=i-2}^{i+2} f_{j} \quad(i=3,4, \cdots, N-2) .
$$

The firing rates thus averaged were plotted as shown at the bottom traces of Figs. 5 and 6.

\section{RESULTS}

Tonic activities of motor units

Before examining reflex responses, we first observed tonic activities of single 

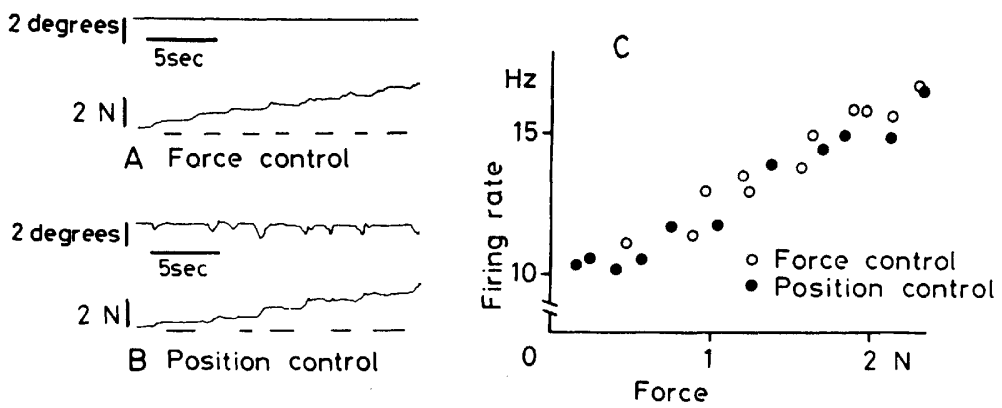

Fig. 3. Tonic activities of a middle finger extensor digitorum communis (EDC) motor unit for two kinds of motor task: force control (A) and position control (B). In both A and $\mathrm{B}$, upper traces are position and lower traces force. Firing rates of the motor unit and net force were averaged over those intervals in which force and position were maintained at relatively constant values (e.g., those marked with bars at the bottom of the traces in $\mathrm{A}$ and $\mathrm{B})$. The firing rates thus averaged are plotted against force in $\mathrm{C}$.

motor units when the subject was executing two types of motor task, force control and constant load position control, to see if behavior of motor units depended on the type of motor task for a given load. Ten motor units were investigated. One of the results is shown in Fig. 3. In force control, the subject maintained isometric force at a given level for a few seconds. The level was intermittently increased in steps (lower trace in Fig. $3 \mathrm{~A}$ ). There was no visible movement of the finger (upper trace in Fig. $3 \mathrm{~A}$ ). Instantaneous firing rates of a single motor unit were averaged over each period during which a steady force was maintained. These periods of steadiness, determined visually, are indicated by the horizontal bars at the bottom of Fig. $3 \mathrm{~A}$. The mean firing rates of the unit are plotted against force with the open circles in Fig. $3 \mathrm{C}$; seven open circles were obtained from the trial of Fig. $3 \mathrm{~A}$ and the other four open circles were obtained from the same motor unit by repeating the experiment. The motor unit in Fig. 3 increased its firing rate linearly with force.

For constant load position control (Fig. 3 B), the subject maintained the 0 degree finger position for a few seconds against a steady force generated by the AC motor. The finger position fluctuated when the force was increased. Instantaneous firing rates of the same motor unit as in the force control were averaged during the periods when both position and force were kept approximately constant (horizontal bars at the bottom of Fig. 3 B). These mean firing rates are plotted against force with the closed circles in Fig. 3 C. No significant difference in mean firing rate $v s$. force relations was found between the two types of motor task for this unit or for any of the other nine motor units investigated.

Before examining the effects of different types of motor task on the stretch reflex response, we need to consider the question of co-contraction of flexor and extensor muscles, since co-contraction enhances the stretch reflex response 
(AKAZAwa et al., 1983). We did not record motor unit activities of the antagonist muscles, so we cannot provide direct evidence about whether co-contraction was present or absent. However, either (a) little, if any, co-contraction was present, or (b) the level of co-contraction was of the same magnitude for both force control and position control. We are confident of this, first, because in preliminary experiments we observed little or no surface EMG activity from the antagonists for either force control or position control. Secondly, as noted above, the firing rate of each EDC motor unit was the same for force control as for position control when the same net force was exerted, suggesting that the force developed by the EDC muscle was identical for both control tasks at any given net force. The force exerted by the flexors, if any, thus did not appear to differ between the two tasks for a given net force, because the net force measured here would be the difference in force between the EDC and the flexor muscles.

\section{Stretch reflex responses in motor unit and EMG activities}

Figure 4 shows discharges of EDC motor units (lower trace) in response to stretch of the muscle (upper trace). Tonic discharges of a motor unit with large positive potentials are clearly seen. In response to stretch, another unit which was silent prior to the disturbance discharged two spikes with large negative potential (shown with asterisks in Fig. 4). In the present study only motor units that showed tonic discharges were analysed.

The effect of two types of motor task, force control and constant load position control, on the stretch reflex response was investigated in eighteen motor units. Ten units showed apparent increases in their firing rates at latencies of 30$60 \mathrm{msec}(49 \pm 9 \mathrm{msec}$, mean \pm S.D.) in response to the stretch, and the remaining eight units showed no clear change in firing rate up to at least $60 \mathrm{msec}$ following the stretch.
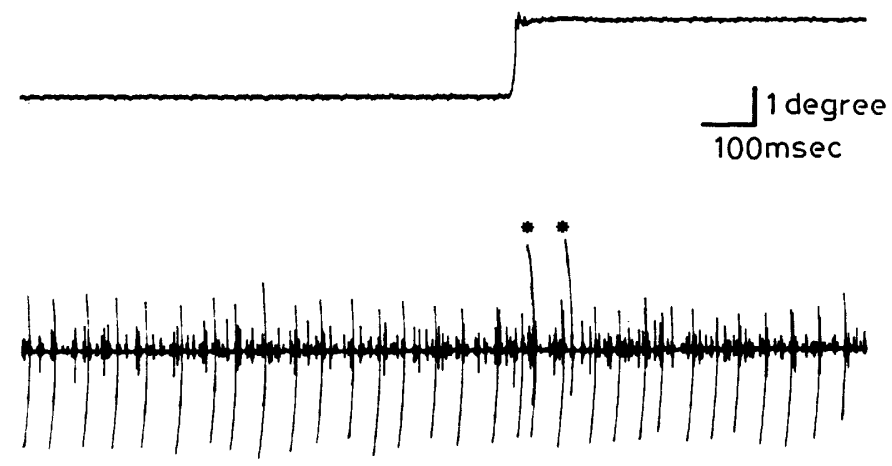

Fig. 4. Record of EDC motor unit discharges in response to quick stretch of the muscle. Upper trace: position of the middle finger, flexion upward. Lower trace: action potentials of motor units, upward negative. Asterisks: discharges of a motor unit which was silent before the onset of the disturbance. 


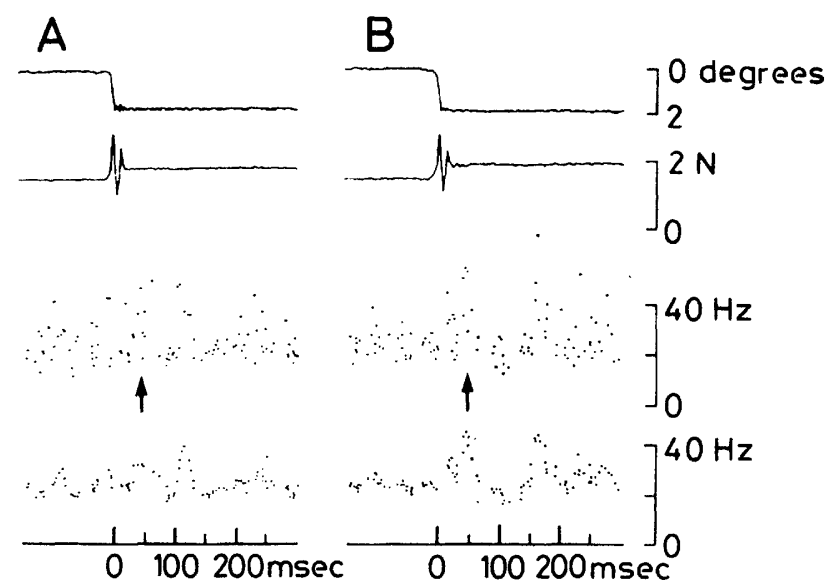

Fig. 5. Reflex responses of a single EDC motor unit evoked by stretching the EDC muscle. A: force control. B: position control. Top traces: finger position (angle of the metacarpophalangeal joint). Resting position is indicated as $\mathbf{0}$ degrees. Flexion of the middle finger is downward. Second traces: force (extension force of the middle finger) measured at the finger tip. Damped oscillation just after the stretch is an artifact. Both position and force are averages of ten trials. Third and bottom traces: superimposed and averaged firing rates of the motor unit, respectively (see text).

Figure 5 shows a typical record of the response observed during force control (A) and constant load position control (B). The first and second traces are recordings of finger position and force, respectively. Stepwise finger flexion, quickly stretching the EDC muscle, was introduced at the time of $0 \mathrm{msec}$. For force control, the finger was clamped at 0 degrees, so fluctuation in the position recording prior to onset of the disturbance should be attributed to noise of the recording system. For position control, the finger was well maintained at 0 degrees with very little fluctuation. The same amount of finger flexion ( 2 degrees) was imposed in both cases. The tonic force before onset of the disturbance was also almost the same, $1.39 \mathrm{~N}$ for force control and $1.42 \mathrm{~N}$ for position control. Damped oscillations in the force recordings observed just after applying the disturbance were due to i) the moments of inertia of the finger and the lever, ii) muscle stiffness, and iii) mechanical vibration of the lever. The third traces are instantaneous firing rates of a single motor unit throughout the ten trials for both control conditions. Increases in the firing rate, which can be considered stretch reflex responses, are seen with latencies of about $45 \mathrm{msec}$ after onset of the disturbance (shown with vertical arrows). This response can be more clearly discerned as a peak with that latency in the averaged recording (bottom trace). The peak of the averaged firing rate with the latency of $45 \mathrm{msec}$ was greater for position control than for force control. The firing rate during the period of $200 \mathrm{msec}$ before imposition of the disturbance in position control $(20.0 \pm 3.6 \mathrm{~Hz})$ was not significantly different from that in force control $(21.6 \pm 7.2 \mathrm{~Hz})$. 


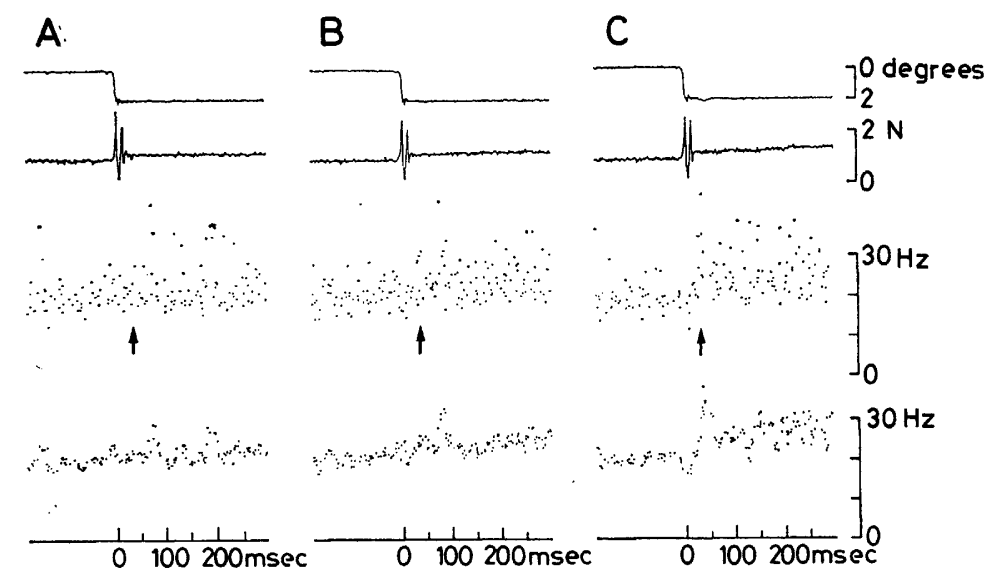

Fig. 6. Reflex responses of a single EDC motor unit to stretching of the muscle in three types of motor task: force control (A), constant load position control (B), and unstable load position control (C). In $C$, the external load increased with flexion of the middle finger. Top traces: finger position (angle of the metacarpophalangeal joint). Second traces: force. Both force and position are the average of ten trials. Third and bottom traces: superimposed and averaged firing rates of the motor unit, respectively. Arrows indicate the time of the short latency reflex response.

For two motor units, we measured stretch reflex responses during unstable load position control as well as force control and constant load position control. Figure 6 shows the responses of one unit. Initial force, finger position, and stretch amplitude were all similar for the three kinds of motor task. Firing rates in the period of $200 \mathrm{msec}$ prior to onset of the disturbance were $20.4 \pm 3.0 \mathrm{~Hz}$ for force control, $21.0 \pm 3.0 \mathrm{~Hz}$ for constant load position control, and $19.7 \pm 3.2 \mathrm{~Hz}$ for unstable load position control. These values were not significantly different from one another. Stretch reflex responses in motor unit activity (shown with arrows in Fig. 6) were observed with latencies of about $40 \mathrm{msec}$. This response was smallest for force control (Fig. $6 \mathrm{~A}$ ), larger for constant load position control (Fig. $6 \mathrm{~B}$ ), and largest for unstable load position control (Fig. $6 \mathrm{C}$ ).

For the ten units showing reflex responses within the first $60 \mathrm{msec}$ from onset of the disturbance, magnitudes of the responses were compared between force control and position control (Fig. 7). Let the tonic firing rate averaged over the $200 \mathrm{msec}$ interval prior to onset of the disturbance be referred to as initial firing rate and the difference between peak firing rate and initial firing rate in the averaged recordings as the stretch-evoked reflex response. The stretch-evoked reflex response is plotted in Fig. 7 against initial firing rate, with triangles for force control, open circles for constant load position control, and closed circles for unstable load position control. Connection of a pair of symbols (circle and triangle) by a line indicates data obtained from the same motor unit. In nine units out of the ten, the stretch-evoked reflex response for constant load position control is greater 


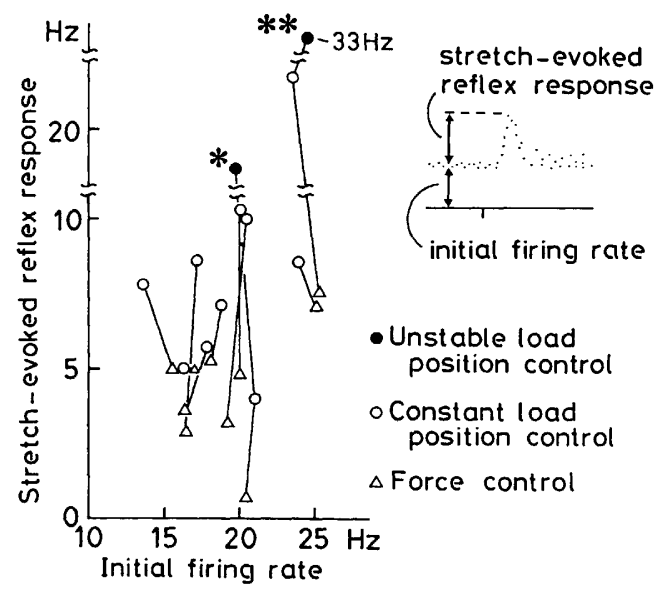

Fig. 7. Comparison of reflex responses of motor units to muscle stretch for three different kinds of motor task: force control (triangles), constant load position control (open circles), and unstable load position control (closed circles). Abscissa: initial firing rates, the tonic firing rate averaged over the period of $200 \mathrm{msec}$ before the onset of the disturbance. Ordinate: stretch-evoked reflex response, the difference between initial firing rate and peak of averaged firing rates (see inset). Data obtained from the same motor unit are connected by a line.

than for force control. The mean and S.D. of the stretch-evoked reflex responses among the ten units was $8.9 \pm 5.0 \mathrm{~Hz}$ for constant load position control and $4.5 \pm$ $2.0 \mathrm{~Hz}$ for force control, and these are significantly different. Note that the initial firing rate in constant load position control, $19.3 \pm 3.4 \mathrm{~Hz}$, did not significantly differ from that in force control, $19.4 \pm 3.4 \mathrm{~Hz}$. As the control task changed from constant load position control to the unstable position control, the stretch-evoked reflex response was further enhanced. One unit (marked with an asterisk in Fig. 7) increased the stretch-evoked reflex response from 4.1 to $18.7 \mathrm{~Hz}$, and another unit (marked with double asterisks) from 21.4 to $33.0 \mathrm{~Hz}$.

To lend further support to the results mentioned above, we examined activities of surface EMG of the EDC muscle under the same experimental conditions as had been taken with single motor unit recordings. Figure 8 shows EMG responses to stretch of the muscle during force control (A) and constant load position control (B). Initial force, indicated at the left, increases from top to bottom. In position control, increase in the EMG activity could be observed in the period of 25-60 msec after onset of the disturbance at any of the initial force levels. Peak of the reflex EMG was usually at about $45 \mathrm{msec}$. These latencies corresponded to those observed in single motor unit activities. Note also that stretchevoked reflex EMGs in force control during the first $25-60 \mathrm{msec}$ after onset of the disturbance were smaller than those in position control for any given initial force. 


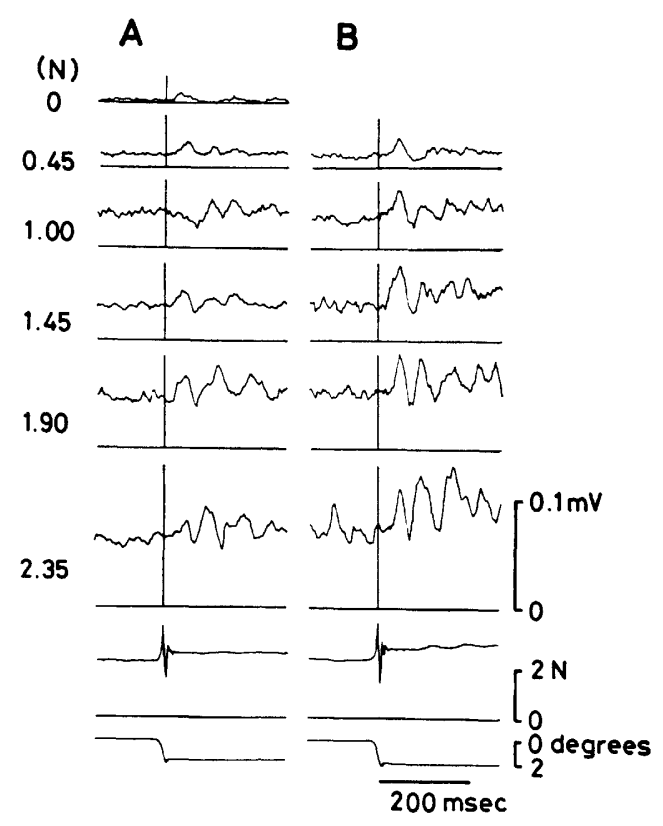

Fig. 8. Rectified and filtered EDC EMG following stretch of the muscle during force control (A) and position control (B). Vertical lines on the recordings represent the time of the stretch. Each trace is the average of 10 responses. Initial force before the stretch is indicated at the left. Bottom traces are force and position recordings of experiments in which initial force was $2.35 \mathrm{~N}$.

\section{DISCUSSION}

One of the main findings of the present study was that stretch reflex responses of single motor units in EDC muscle with latencies of 30-60 msec were modulated according to type of motor task. The responses were enhanced during position control as compared with those during force control. Such modulation of the stretch reflex responses was also observed in the surface EMGs.

In contrast to the situation of a tonic contraction, the magnitude of the stretch reflex response induced during phasic movement changes according to phase of the movement (DUFRESNE et al., 1980) and velocity of the movement (GotTLIEB and Agarwal, 1979). During tonic contraction, the stretch reflex response is modulated by various factors, such as magnitude and velocity of length perturbation (GotTLIEB and AGARWAL, 1979), instruction of how to react to the disturbance (see the introduction), level of tonic contraction, predictability of the disturbance, and co-contraction of antagonist muscles. In the present study, we attempted to keep these factors constant. We set the magnitude and velocity of the stretch constant: 2 degrees and 250 degrees/sec, respectively. The instruction of how to react to the disturbance was consistent throughout: do not react to the disturbance. 
The stretch reflex response is influenced by the level of tonic contraction, which is indicated by the background EMG (MARSDEN et al., 1976; ILES, 1977; GotTlieb and Agarwal, 1979). The higher the background EMG, the larger the reflex response. In the present study, we showed that a motor unit would discharge at the same tonic firing rate during force control as during position control if the net force was constant (see Figs. 3, 5, and 6), so modulation of the stretch reflex response observed here could not be attributed to a change in tonic activity of the muscle.

Recently, Rothwell et al. (1980) showed that the response in the flexor pollicis longus with latencies as short as $50 \mathrm{msec}$ can be considerably modified when the subject is able to predict the timing of the stimulus accurately. They attribute this modification to an interaction between a reflex of long latency and a subsequent very rapid voluntary event, occurring early because of the predictability of the stimulus. In the present study, the subject was instructed not to react to the disturbance, which was introduced at random so that the subject could not accurately predict when it would occur; so modulation of the stretch reflex observed in this study could not have resulted from the predictability of the disturbance.

BURKE et al. (1980) demonstrated that the $\alpha-\gamma$ balance of the human pretibial muscle is changed by such peripheral stimuli as vibratory cutaneous stimulation and passive stretch of the muscle. LUNDBERG et al. (1977) have further shown that the interneuronal transmission in the $\mathrm{Ib}$ reflex pathway is facilitated at a segmental level by impulses from cutaneous afferents. These peripheral effects, however, could be excluded here, since both finger position and force during the tonic phase were kept constant for both position control and force control, giving rise to the same amount of tonic mechanical stimuli to the skin and proprioceptors regardless of the type of motor task.

Recently, HAGBARTH and his colleagues (1981) have demonstrated that a sudden joint displacement may give rise to successive peaks of spindle afferent discharges, presumably resulting from mechanical oscillations initiated by the impact. This result strongly suggests a high sensitivity of the spindle afferent to oscillation. In this study, force recordings exhibited such damped oscillations just after the onset of the disturbance (Figs. 5 and 6), which thus could have acted as a stimulus to the muscle spindle and affected the reflex response. As shown in the force recordings, the oscillation for force control and position control were identical in pattern and magnitude, so the contribution of the oscillation to the reflex response should have been similar for the two situations.

Houk (1979) has suggested that there is no evidence for adaptive control of gain in the stretch reflex loop and that any change in the stretch reflex responsiveness reported so far can be explained by nonlinearities in the properties of the reflex loop or by reaction time movements. In the present study, initial position, force, and motoneuronal output were all held constant for both types of motor task, so changes in stretch reflex responses observed in the present study were 
unlikely to have been due to nonlinearities. Furthermore, the effect of reaction time movement should have been negligible in the response observed during the first 30-60 msec following the disturbance.

All these considerations suggest that the gain in the short latency stretch reflex loop can be modulated according to type of motor task. We could not determine from the present results whether this modulation resulted from changes in muscle spindle sensitivity through the fusimotor system, changes of transmission in reflex pathways from Ib afferents to motoneurons, or changes in properties of the central connections. In any case, however, central motor processes most certainly control the gain of the short latency stretch reflex loop independently of the tonic motoneuronal output.

Out of the eighteen motor units investigated, eight units showed no obvious changes in firing rates with the latencies of $30-60 \mathrm{msec}$ in response to quick stretch of the muscle. First, the intensity of the mechanical stimulus ( 2 degrees) may not have been strong enough for the motor units to elicit the reflex response. Secondly, those units might have already reached the maximum firing rate level during the execution of force control or position control before the disturbance was imposed. This possibility, however, appears to be remote. The operating force employed in the stretch reflex experiments was less than $2 \mathrm{~N}$ (about $20 \%$ of the maximum isometric force), and over this force range, ten motor units investigated still increased their firing rates with increases in force (see the section Tonic activities of motor units). Finally, BAWA and TATTON (1979) showed in monkeys that each peak of the EMG response to sudden stretch of a muscle largely results from the firing of a separately responding subgroup of single motor units. Although such findings have never been reported in man, the eight units showing no obvious short latency responses might belong to such subgroups that are responsible for the longer latency EMG peaks.

The authors are much indebted to Prof. R. B. Stein of the University of Alberta for reading and commenting on the manuscript and to Dr. P. D. Andrew of Bobath Hospital for the English corrections.

\section{REFERENCES}

Akazawa, K., Milner, T. E., and Stein, R. B. (1983) Modulation of reflex EMG and stiffness in response to stretch of human finger muscle. J. Neurophysiol., 49: 16-27.

Basmajian, J. V. (1974) Muscles Alive, 3rd ed., Williams and Wilkins, Baltimore, p. 37.

Bawa, P. and Tatton, W. G. (1979) Motor unit responses in muscles stretched by imposed displacements of the monkey wrist. Exp. Brain Res., 37: 417-437.

Burke, D., McKeon, B., and Westerman, R. A. (1980) Induced changes in the thresholds for voluntary activation of human spindle endings. J. Physiol. (Lond.), 302: 171-181.

Colebatch, J. G., Gandevia, S. C., Mcloskey, D. I., and Potter, E. K. (1979) Subject instruction and long latency reflex responses to muscle stretch. J. Physiol. (Lond.), 292: 527534.

Crago, P. E., Houk, J. C., and Hasan, Z. (1976) Regulatory actions of human stretch reflex. 


\section{J. Neurophysiol., 39: 925-935.}

Dufresne, J. R., Soechting, J. F., and Terzuolo, C. A. (1980) Modulation of the myotatic reflex gain in man during intentional movements. Brain Res., 193: 67-84.

Evarts, E. V. and Granit, R. (1976) Relations of reflexes and intended movements. Prog. Brain Res., $44: 1-14$.

EvarTs, E. V. and TANJI, J. (1974) Gating of motor cortex reflexes by prior instruction. Brain Res., 71 : 479-494.

Gottlieb, G. L. and Agarwal, G. C. (1979) Response to sudden torques about ankle in man: Myotatic reflex. J. Neurophysiol., 42: 91-106.

HagbarTH, K.-E. (1967) EMG studies of stretch reflexes in man. In: Recent Advances in Clinical Neurophysiology (Electroencephalogr. Clin. Neurophysiol., Suppl. 25), ed. by WIDEN, L. EIsevier, Amsterdam, pp. 74-79.

Hagbarth, K.-E., HäGglund, J. V., Wallin, E. U., and Young, R. R. (1981) Grouped spindle and electromyographic responses to abrupt wrist extension movements in man. J. Physiol., (Lond.), 312: 81-96.

Hammond, P. H. (1956) The influence of prior instruction to the subject on an apparently involuntary neuro-muscular response. J. Physiol. (Lond.), 132: 17P-18P.

Houk, J. C. (1979) Regulation of stiffness by skeletomotor reflexes. Annu. Rev. Physiol., 41: 99-114.

ILES, J. F. (1977) Responses in human pretibial muscles to sudden stretch and to nerve stimulation. Exp. Brain Res., 30: 451-470.

Kanosue, K., Akazawa, K., and FujI, K. (1980) Motor servo gain control examined by tendon jerk study. Proc. Int. Univ. Physiol. Sci. (Budapest), 14: 502.

Lundberg, A., Malmaren, K., and Schomburg, E. D. (1977) Cutaneous facilitation of transmission in reflex pathways from Ib afferents to motoneurones. J. Physiol. (Lond.), 265: 763780.

Marsden, C. D., Merton, P. A., and Morton, H. B. (1976) Servo action in the human thumb. J. Physiol. (Lond.), 257: 1-44.

Rothwell, J. C., Traub, M. M., and Marsden, C. D. (1980) Influence of voluntary intent on the human long-latency stretch reflex. Nature, 286: 496-498. 